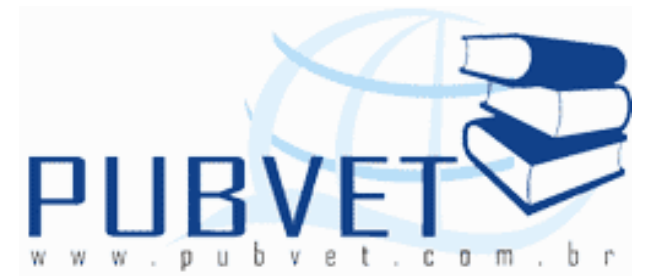

PUBVET, Publicações em Medicina Veterinária e Zootecnia.

\title{
Redução de fratura diafisária tibial em chinchila (Chinchilla lanigera) - Relato de caso
}

\author{
Mariana Batista Andrade ${ }^{\mathbf{1}}$, André Luiz Quagliatto Santos ${ }^{2}$, Dayane Olímpia \\ Gomes $^{3}$, Andréa Cristina Scarpa Bosso ${ }^{4}$, Fernando Moraes Machado Brito ${ }^{4}$
}

Laboratório de Ensino e Pesquisa em Animais Silvestres - LAPAS, FAMEV/UFU. e-mail: quagliatto@famev.ufu.br 1. Docente. 2. Mestranda. 3. Residente do Laboratório de Doenças Infecto-contagiosas, FAMEV/UFU. 4. Doutorandos da Faculdade de Ciências Agrárias e Veterinárias da Universidade Estadual Paulista Júlio de Mesquita Filho - FCAV UNESP, Jaboticabal-SP.

\section{Resumo}

Uma chinchila fêmea, com idade entre oito e 10 meses foi atendida no HVUFU, onde diagnosticou-se fratura oblíqua longa na diáfise da tíbia direita. Realizou-se a fixação interna da lesão, por meio da colocação de um pino intramedular de Steinmann associado à cerclagem com fios de aço. Posteriormente, o membro foi imobilizado com tala de PVC e o animal fez uso do colar elizabetano, durante 30 dias. No pós-operatório (PO), recebeu cefazolina sódica 200,0 mg/mL, na dose de 20,0 mg/kg, 12/12 horas, por via IM, durante sete dias. Curativos diários na ferida cirúrgica foram feitos com solução fisiológica e iodopolvidona $0,2 \%$, até a retirada dos pontos, que ocorreu no $10^{\circ}$ dia de PO. Efetuaram-se, ao total, quatro tomadas 
radiográficas para avaliação do processo de cicatrização: imediatamente após a cirurgia, ao 70 e $15^{\circ}$ dias de PO, e três meses após o tratamento cirúrgico. A primeira permitiu avaliar o alinhamento da fratura e a posição do implante; as duas subsequentes demonstraram a permanência da correta posição do pino intramedular; e a quarta imagem revelou correto alinhamento do osso e presença de um calo ósseo já calcificado na região acometida, onde a cicatrização óssea estava completa. Decorridos três meses da cirurgia, o membro mostrava-se funcional, pela capacidade de locomoção ágil do animal. O método de redução de fratura utilizado mostrou ser eficaz na espécie em questão, por promover estabilidade local durante o período de reparação óssea e permitir um retorno precoce da função do membro.

Palavras-chave: cirurgia ortopédica, roedores histricomorfos, animais silvestres

\title{
Reduction of tibial diaphyseal fracture in chinchilla (Chinchilla lanigera) - A case report
}

\begin{abstract}
A female chinchilla, 8 to 10 months old, was treated at the Veterinary Hospital of the Federal University of Uberlândia, where a long oblique fracture of the diaphysis of the right tibia was diagnosed. The lesion was fixed internally using an intramedullary Steinmann pin associated with cerclage with steel wires. The member was then immobilized with a PVC splint and the animal wore a space collar for 30 days. Postoperatively, the animal was given intramuscular injections of $20 \mathrm{mg} / \mathrm{kg}$ of cephazoline sodium $200 \mathrm{mg} / \mathrm{mL}$ at 12-hour intervals for seven days. The surgical wound was cleaned and dressed daily using a physiological solution and $0.2 \%$ iodopovidone until the stitches were removed on the $10^{\text {th }}$ day PO. A total of four X-rays were taken to evaluate the healing process: immediately after surgery, on the $7^{\text {th }}$ and $15^{\text {th }}$ day PO, and three
\end{abstract}


months after the operation. The first X-day served to evaluate the alignment of the fracture and the position of the implant. The two subsequent $X$-rays confirmed that the intramedullary pin remained in the correct position, and the fourth image revealed the correct alignment of the bone and the presence of a calcified bone callus in the affected region where healing was already complete. Therefore, three months after surgery, the member had regained its functionality, as indicated by the animal's agile movements. The fracture reduction method used here proved effective in the species in question, promoting local stability during the bone repair process and allowing for the early recovery of the member's function.

Keywords: orthopedic surgery, hystricomorph rodents, wild animals

\section{INTRODUÇÃO}

Espécie animal exótica no Brasil e originária dos Andes, a chinchila é amplamente comercializada como animal de estimação (PESSOA, 2007) e para produção de pele. Esta é uma atividade relativamente nova e atende, atualmente, $50 \%$ da demanda do mercado internacional, o qual é consideravelmente exigente com relação à qualidade do produto (ANTÔNIO et al., 2007a).

Por serem bastante ativas e curiosas, comumente sofrem quedas e outros tipos de traumatismos, ao explorarem o ambiente que as rodeia. Tal fato implica na ocorrência, não incomum, de lesões ao sistema musculoesquelético, como as fraturas diafisárias tibiais, que são frequentemente oblíquas, espirais, fragmentares e do tipo expostas, em virtude da escassez de tecidos moles ao redor do osso (JOHNSON e HULSE, 2005b; POPE, 2005).

A localização anatômica da tíbia reflete a possibilidade de utilização de uma variedade de técnicas, como bandagens, pinos intramedulares, fixadores esqueléticos externos, placas e parafusos ósseos na reparação de fraturas 
(DENNY e BUTTERWORTH, 2006). Deve-se utilizar a cerclagem completa para envolver fissuras presentes no local e impedir que elas se alarguem ao longo do processo de redução (STRAW e STHEPHEN, 2005). Um tratamento conservador com talas e pensos é indicado para fraturas fechadas, não deslocadas ou em galho verde (em animais imaturos) (JOHNSON e HULSE, 2005b).

Em virtude do crescente aumento das criações de chinchilas, estudos têm sido direcionados para a descoberta de particularidades fisiológicas (SILVA et al., 2005; ANTÔNIO et al., 2007a; ANTÔNIO et al., 2007b), anatômicas (ADARO et al., 1998; MARTINEZ et al., 2000; NEVES et al., 2006, CASTRO et al., 2007) e de patologias importantes que acometem esse animal (ILHA et al., 2000; LAZZARI et al., 2001). No âmbito da clínica cirúrgica, pode-se encontrar relatos científicos sobre hérnia diafragmática (DALL, 1967), urolitíase (JONES et al., 1995) e cesariana (STEPHENSON, 1990) na referida espécie.

Este caso clínico descreve os resultados obtidos com a utilização do pino intramedular de Steinman associado à cerclagem com fio de aço como método de fixação interna para redução de fratura diafisária tibial em chinchila.

\section{CASUÍSTICA}

Em junho de 2006, uma chinchila fêmea e com idade entre oito e 10 meses foi atendida no Hospital Veterinário (HV) da Universidade Federal de Uberlândia (UFU). O proprietário relatou que há uma semana o recinto do animal havia caído de uma altura considerável, e que após o ocorrido o paciente deixou de apoiar o membro pélvico direito e apresentou hiporexia. No primeiro atendimento médico, realizado em uma clínica particular, o membro foi imobilizado por uma tala, que, segundo o proprietário foi roída pelo animal.

Durante o exame físico, a palpação revelou crepitação e certo grau de rotação no terço médio da perna direita. A paciente apresentou parâmetros 
vitais normais: $37,7{ }^{\circ} \mathrm{C}$ de temperatura retal, freqüências cardíaca e respiratória de 160 batimentos por minuto e 88 movimentos por minuto, respectivamente. Através de imagens radiográficas obtidas em posição ventrodorsal e látero-lateral do membro afetado, diagnosticou-se fratura tibial oblíqua longa, com deslocamento cranial do coto distal do osso (Fig.1- A). Em bom estado geral e se alimentando, a paciente recebeu uma imobilização temporária do membro pélvico direito e retornou para casa, onde ficaria em jejum sólido por 12 horas e jejum hídrico por seis horas, para ser submetida à cirurgia na manhã seguinte.

O animal foi anestesiado com tiletamina-zolazepan $50,0 \mathrm{mg} / \mathrm{mL}$, na dose de $30,0 \mathrm{mg} / \mathrm{kg}$ por via IM, posicionado e fixado na mesa cirúrgica em decúbito lateral esquerdo. Procedeu-se a tricotomia do membro pélvico direito e posterior anti-sepsia com álcool-iodo-álcool. Após colocação do pano de campo, foi feita uma incisão de pele de aproximadamente cinco centímetros na face lateral do terço médio da perna, seguida de divulsão do espaço subcutâneo, incisão da fáscia e afastamento dos músculos da região, permitindo o acesso e exposição do segmento ósseo fraturado.

Com o auxílio de uma furadeira de Jacob, um pino de Steinmann 1,0 x 4,8, foi introduzido através do canal medular (CM) do segmento ósseo proximal, perfurou a articulação do joelho e se exteriorizou através da pele, até que a extremidade oposta do pino também entrasse no $\mathrm{CM}$. Posteriormente à coaptação dos segmentos tibiais, o pino foi introduzido em sentido contrário, permitindo sua passagem, através da linha de fratura, para o CM da extremidade distal da tíbia, até próximo à articulação tibiotársica. A porção excedente do pino foi cortada com uma cisalha, seguida de sepultamento do mesmo com auxílio de um recalcador de pinos e um martelo leve. Assim que se verificou o alinhamento do eixo ósseo e a introdução completa do pino no CM, os fragmentos ósseos foram anatomicamente reposicionados e envoltos por duas cerclagens com fios de aço no 0 . Reaproximou-se a musculatura e 
fáscia com pontos em " $X$ " seguida de abolição do espaço morto com padrão "zig-zag", ambas com fio cat-gut 3-0. A pele foi suturada com fio nylon 3-0, utilizando-se pontos simples separados.

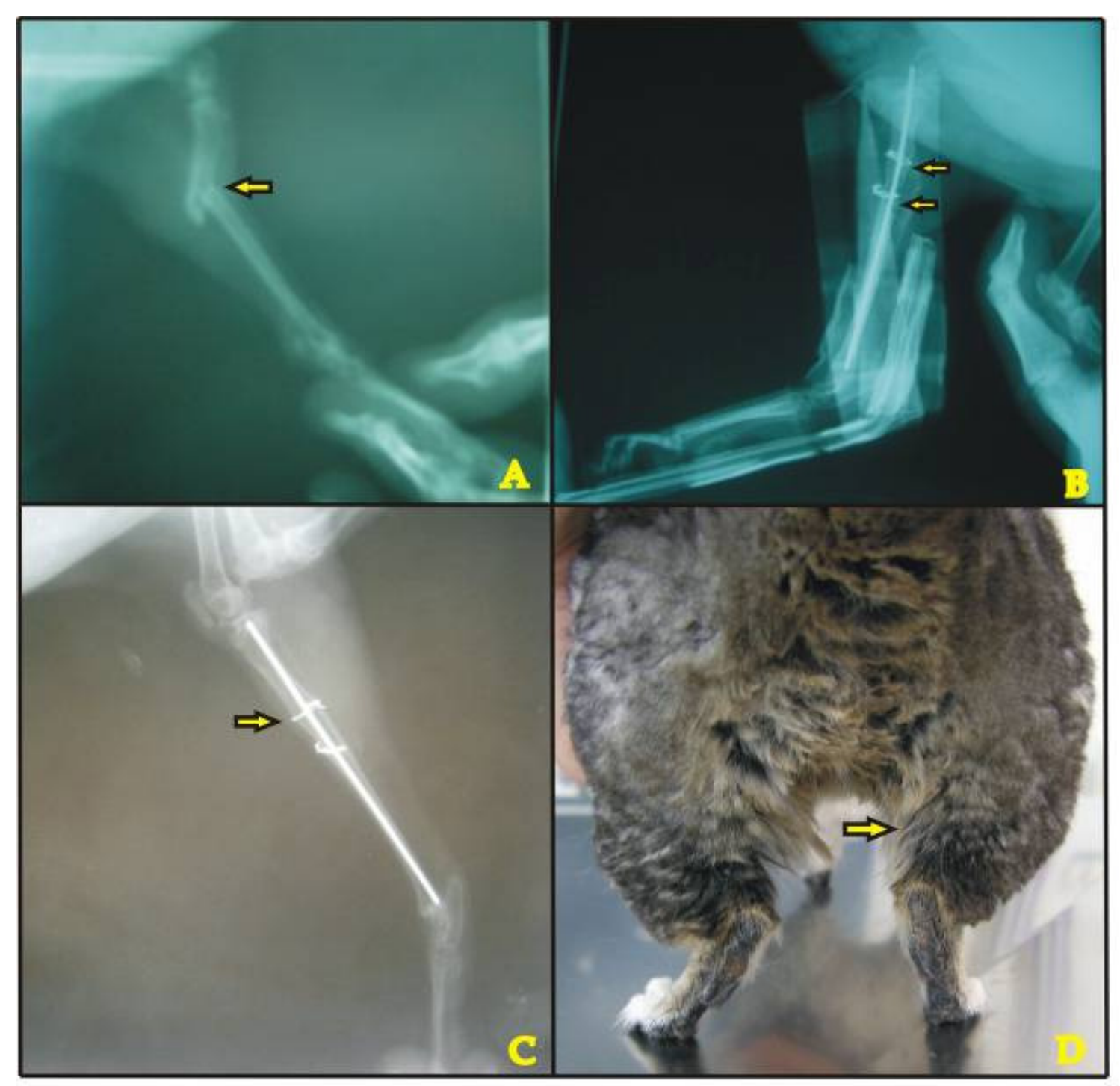

Figura 1 - (A) Vista látero-lateral da fratura oblíqua longa do osso tíbia direito em chinchila. Deslocamento cranial do coto distal à fratura (seta). (B) Aspecto da fratura reduzida, logo após o término da cirurgia. Fragmentos ósseos envoltos por fios de aço (setas). (C) Imagem radiográfica do membro acometido três meses após a cirurgia. Cicatrização óssea completa e presença de um discreto calo ósseo (seta). (D) Apoio normal do membro acometido. Região onde a fratura foi reduzida (seta) 
No período pós-operatório (PO), o animal foi mantido com colar elizabetano e o membro imobilizado em sua posição anatômica com tala de PVC, durante 30 dias. Realizaram-se curativos diários na ferida cirúrgica com solução fisiológica e iodopolvidona $0,2 \%$, até a retirada dos pontos de pele, no $10^{\circ}$ dia de PO. A paciente recebeu cefazolina sódica $200,0 \mathrm{mg} / \mathrm{mL}$, na dose de 20,0 $\mathrm{mg} / \mathrm{kg}, 12 / 12$ horas, por via IM, durante sete dias. Efetuaram-se tomadas radiográficas do membro imediatamente após a cirurgia, ao sétimo e $15^{\circ}$ dia de PO, e decorridos três meses da cirurgia, para avaliação do processo de cicatrização óssea.

\section{DISCUSSÃO}

O processo de consolidação de fraturas tem sido estudado em inúmeras espécies animais. Segundo Nunamaker (1998), pesquisas em camundongo, cavalo, rato, gato, pombo, primatas, coelhos e outras espécies menos comuns vêm divulgando resultados positivos. Em função da complexidade biológica envolvida na formação óssea, o assunto ainda é um campo aberto para pesquisa, considerando-se o fato de que cada pesquisa revela vantagens e desvantagens próprias (MATOS, 2001).

Observa-se, mediante a popularização da chinchila como animal de companhia, o aumento da demanda por serviços veterinários prestados a esses animais. Tal fato implica na necessidade de se enriquecer o acervo de informações técnico-científicas relacionadas à espécie em campos fundamentais, como a cirurgia ortopédica, particularmente importante em animais curiosos e agitados por natureza.

Segundo Pessoa (2007) a anatomia esquelética e muscular dos roedores exóticos é similar à dos animais domésticos. Consequentemente, o tratamento deve ser baseado no tipo e localização da fratura, tamanho e idade do animal, 
número de ossos envolvidos e viabilidade dos tecidos moles da região (DE YOUNG e PROBST, 1993).

Ao ser recebido, o paciente usava uma tala confeccionada com material de PVC no membro acometido, para diminuir o desconforto e prevenir danos adicionais aos tecidos moles, conforme recomendando por Johnson e Hulse (2005a). Não se utilizou esse método como tratamento definitivo, pois a perda de continuidade associada ao deslocamento do coto distal do osso tornava a fratura instável, justificando a correção cirúrgica através da fixação interna (WISS, 2001).

Optou-se pelo tratamento cirúrgico com pino intramedular associado à cerclagem com fios de aço. A técnica é indicada para se obter maior estabilidade em ossos longos (PESSOA, 2007) que apresentem fraturas oblíquas longas com mínima fragmentação (POPE, 2005) e seu uso é recomendado em roedores de médio a grande porte. Além da praticidade e baixo custo, a escolha do método foi determinada pelo pequeno porte do paciente e o material cirúrgico disponível. Um pino intramedular de Steinmann $1,0 \times 4,8$ foi suficiente para preencher quase todo o canal medular (PESSOA, 2007) resultando em maior efeito estabilizador e alinhamento do segmento ósseo em decorrência do íntimo contato do pino com o córtex ósseo circunjacente (DEAN, 2005).

Os fios de aço funcionaram como suporte adicional à estabilização da fratura e auxiliaram a manobra de colocação do pino no interior da cavidade medular, impedindo que as fissuras presentes se alargassem, conforme relata Pessoa (2007). Entretanto, não devem ser utilizados como único meio de fixação do eixo tibial por serem incapazes de suportar o estresse produzido pela sustentação de peso precoce (POPE, 2005). Como suporte adicional ao processo de fixação interna, utilizou-se a coaptação externa do membro com tala de PVC durante 30 dias, para aumentar a rigidez da fixação e impedir o apoio precoce do membro (DENNY e BUTTERWORTH, 2006). 
Segundo Johnson e Hulse (2005a), a avaliação da cicatrização óssea se faz através de tomadas radiográficas seqüenciais no $\mathrm{PO}$, obtidas a cada quatro a seis semanas. A primeira, realizada ao final da cirurgia, permitiu avaliar o alinhamento da fratura e a posição do implante (Fig.1- B), conforme o recomendado pelos referidos autores. Duas radiografias seqüenciais foram obtidas nos dias sete e 15 de PO e demonstraram a permanência da correta posição do implante, mas não forneceram evidências de formação óssea. A última avaliação, realizada três meses após o tratamento cirúrgico, revelou correto alinhamento do osso e presença de um calo ósseo já calcificado na região acometida (Fig.1- C). Provavelmente um período maior de avaliação radiográfica seria necessário para acompanhar a evolução da cicatrização óssea, entretanto, o número de imagens obtidas foi determinado pela disponibilidade do proprietário em conduzir o animal ao HV-UFU.

Decorridos três meses da cirurgia, o paciente mostrava apoio e função do membro praticamente normais (Fig.1- D), refletidos na capacidade de locomoção ágil e na imagem radiográfica, que demonstrava completa cicatrização óssea.

\section{CONCLUSÃO}

O método de redução de fratura utilizado mostrou ser eficaz na espécie em questão, por promover estabilidade local durante o período de reparação óssea e permitir um retorno precoce da função do membro.

\section{REFERÊNCIAS}

ADARO, L.; OROSTEGUI, C.; CEPEDA, R.; OLIVARES, R.; SOTO, M. Troncos arteriales del aparato reproductor de la chinchilla macho (Chinchilla laniger GREY), en cautiverio. Revista Chilena de Anatomía, v. 16, n. 2, p. 225-228, 1998.

ANTÔNio, S. D.; VelHo, J. P.; CARVALHO, P. A.; BACKeS A. A.; SANCHEZ, L. M. B.; VelHo, I. M. P. H. Composição corporal e exigências líquidas em energia e proteína para ganho de 
peso em chinchilas (Chinchilla lanígera). Ciência e Agrotecnologia, v. 31, n. 2, p. 479-484, 2007a.

ANTÔNiO, S. D.; VelHo, J. P.; CARVALHO, P. A.; BACKeS A. A.; SANCHEZ, L. M. B.; VelHo, I. M. P. H. Predição da composição corporal e exigências líquidas de macrominerais para ganho de peso de chinchila (Chinchilla lanigera). Ciência e Agrotecnologia, v. 31, n. 2, p. 548-533, 2007b.

CASTRO, T. F.; PEREIRA, P. C. G.; PEREIRA, M. A. M.; BOMBONATO, P. P.; RICKES, E. M. Formação do sistema venoso portal em Chinchilla lanígera. Brazilian Journal of Veterinary Research and Animal Science, p. 44, v. 1, p. 44-48, 2007.

DALL, J. A. Diaphragmatic hernia in a chinchilla. Veterinary Record, v. 81 n. 23, p. 599, 1967.

DEAN, P. W. Colocação de pinos múltiplos. In: BOJRAB, M. J. Técnicas atuais em cirurgia de pequenos animais. 3. ed. São Paulo: Roca, 2005. p. 758-761.

DENNY, H. R.; BUTTERWORTH, S. J. Opções no tratamento das fraturas. In: ortopédica em cães e gatos. 4. ed. São Paulo: Roca, 2006. p. 67-102. . Cirurgia

DE YOUNG, D. J.; PROBST, C. W. Methods of internal fracture fixation. In: SLATTER, D. Textbook of small animal surgery. Philadelphia: Saunders, 1993. v. 2, p. 1610-1631.

ILHA, M. R. S.; JÚNIOR, P. S. B.; SANCHES, A. W. D.; BARROS, C. S. L. Embolia pulmonar trofoblástica em chinchilas (Chinchilla laniger). Ciência Rural, v. 30, n. 5, p. 903-904, 2000.

JOHNSON, A. L.; HULSE, D. A. Fundamentos da cirurgia ortopédica e tratamento de fraturas. In: FOSSUM, T. W. Cirurgia de pequenos animais. 2. ed. São Paulo: Roca, 2005a. p. 823892.

JOHNSON, A. L.; HULSE, D. A. (2005b). Tratamento de fraturas específicas. In: FOSSUM, T. W. Cirurgia de pequenos animais. 2. ed. São Paulo: Roca, 2005b. p. 900-1011.

JONES, R. J.; STEPHENSON, R.; FOUNTAIN, D.; HOOKER, R. Urolithiasis in a chinchilla. Veterinary Record, v. 136, n. 15, p. 400, 1995.

LAZZARI, A. M.; VARGAS, A. C.; DUTRA, V.; GRAÇA, D. L.; HEADLEY, S. A.; COSTA, M. M. Agentes infecciosos isolados de Chinchilla laniger - relato de casos. Ciência Rural, v. 31, n. 2, p. 337-340, 2001.

MARTINeZ, M.; MARTINeZ, F. E.; PINHEIRO, P. F. F.; ALMEIDA, C. C. D.; SEGATELLI, T. M. Watanabe II-S. Scanning electron microscopic study of the tongue of chinchilla (Chinchilla laniger). Revista Chilena de Anatomía, v. 18, n. 1, p. 53-59, 2000.

MATOS, M. A.; GONÇALVES, R. R. Modelo experimental de osteotomia em coelhos imaturos. Acta Ortopédica Brasileira, v. 9, p. 21-26, 2001.

NEVEZ, M. M.; MORAIS, D. B.; BARBOSA, L. P.; GOMES, M. G.; BALARINE, M. K. Preservação do sistema genital de chinchila (Chinchilla lanigera) para avaliação em microscopia de luz. Arquivo Brasileiro de Medicina Veterinária e Zootecnia, v. 58, n. 6, p. 1247-1248, 2006. 
PESSOA, C. A. Roedores de companhia (Hamster, Gerbil, Cobaia, Chinchila, Rato). In: CUBAS, Z. S.; SILVA, J. C. R.; CATÃO-DIAS. Tratado de animais selvagens. São Paulo: Roca, 2007. p. $432-474$.

POPE, E. R. Fixação das fraturas tibiais. In: BOJRAB, M. J. Técnicas atuais em cirurgia de pequenos animais, 3. ed. São Paulo: Roca, 2005, p. 678-684.

SILVA, T. O.; KREUTZ, L. C.; BARCELLOS, L. J. G.; BORELLA, J. SOSO, A. B.; SOUZA, C. Reference values for chinchilla (Chinchilla laniger) blood cells and serum biochemical parameters. Ciência Rural, v. 35, n. 3, p. 602-606, 2005.

STEPHENSON, R. S. Caesarean section in a chinchilla. Veterinary Record, v. 126, n. 15, p. $370,1990$.

STRAW, R. C.; WITHROW, S. J. Colocação de fios de aço de cerclagem (2005). In:BOJRAB, M. J. Técnicas atuais em cirurgia de pequenos animais, 3. ed. São Paulo: Roca, 2005, p. 678-684.

NUNAMAKER, D. M. Experimental model of fracture repair. Clinical Orthopaedics and Related Research, v. 355, p. 57-65, 1998.

WISS, D. A. What's New in Orthopaedic Trauma. The Journal of Bone and Joint Surgery, $v$. 83, p. $1762-1772,2001$. 